\title{
A micrometer scale and low temperature PZT thick film MEMS process utilizing an aerosol deposition method
}

\author{
Xuan-Yu Wang ${ }^{\mathrm{a}, *}$, Chi-Yuan Lee ${ }^{\mathrm{b}}$, Cheng-Jien Peng ${ }^{\mathrm{c}}$, \\ Pei-Yen Chen ${ }^{\mathrm{d}}$, Pei-Zen Chang ${ }^{\mathrm{a}}$ \\ ${ }^{a}$ Institute of Applied Mechanics, National Taiwan University, Taipei, Taiwan \\ ${ }^{\mathrm{b}}$ Department of Mechanical Engineering, Fuel Cell Research Center, Yuan Ze University, Taoyuan, Taiwan \\ ${ }^{\mathrm{c}}$ Materials Research Laboratories, Industrial Technology Research Institute, Hsinchu, Taiwan \\ ${ }^{\mathrm{d}}$ Chung-Shan Institute of Science and Technology, Taoyuan, Taiwan
}

Received 22 April 2007; received in revised form 14 November 2007; accepted 14 November 2007

Available online 3 December 2007

\begin{abstract}
An aerosol deposition method and its lift-off process have been integrated for fabricating thick lead-zirconate-titanate (PZT) films for MEMS applications. The thickness of the deposited PZT films can be controlled over a wide range from $2 \mu \mathrm{m}$ to more than $18 \mu \mathrm{m}$. In an area of $60 \mathrm{~mm} \times 70 \mathrm{~mm}$, an optimum deposition rate of $5 \mu \mathrm{m} / \mathrm{h}$ has been observed. For $13 \mu \mathrm{m}$ thick PZT films, the minimum linewidth of $30 \mu \mathrm{m}$ has been achieved. The fabricated thick PZT films exhibit a strong perovskite phase, after aerosol deposition at room temperature. To verify the functionality of deposited PZT films, a $7 \mu \mathrm{m} \times 700 \mu \mathrm{m} \times 900 \mu \mathrm{m}$ cantilever-beam resonator has been fabricated. The resonance frequencies of the PZT cantilever resonator were measured and found to be similar to results of the finite element simulation. Finally, a functional $5 \mu \mathrm{m} \times 650 \mu \mathrm{m} \times 1200 \mu \mathrm{m}$ PZT cantilever resonator was realized by annealing the PZT film at $500{ }^{\circ} \mathrm{C}$.
\end{abstract}

(C) 2007 Elsevier B.V. All rights reserved.

Keywords: PZT thick film; Aerosol deposition method

\section{Introduction}

Lead-zirconate-titanate (PZT) is a popular piezoelectric material in microelectromechanical systems (MEMS). It has been used in a large variety of micro-device applications, such as micropump [1], micromotor [2], touch probe sensor [3], micropower harvesting [4], and micro-piezoelectric transformer [5,6]. Typical deposition methods of PZT in micromachining include sol-gel coating [7] and sputtering [8]. PZT film thickness deposited by these two methods is usually less than $5 \mu \mathrm{m}$. For some particular MEMS devices such as the micro-power harvester and micro-piezoelectric transformer, higher power efficiency relies on thicker piezoelectric layers, especially when

\footnotetext{
* Corresponding author at: R433, Institute of Applied Mechanics, National Taiwan University, No. 1, Sec. 4, Roosevelt Road, Taipei 106, Taiwan. Tel.: +886 2 33665646x111; fax: +886233665638.

E-mail address: xywang@mems.iam.ntu.edu.tw (X.-Y. Wang).
}

the device pattern is constrained. In the trend to reduce the dimensions of micro-devices for system integration, effective deposition techniques of thick films are therefore important.

In recent years, many deposition methods of thick PZT films have been developed. By using proper solvent in PZT sol-gel, thick films can be fabricated without repeating too many coating iterations $[9,10]$. For example, Gentry et al. deposited PZT films by using repetitive dip coating [10]. PZT thickness from 3 to $100 \mu \mathrm{m}$ has been demonstrated. Jacobsen et al. developed a hollow cathode sputtering device, which can deposit PZT film as thick as $20 \mu \mathrm{m}$ [11]. In addition, screen printing [12,13], a hydrothermal method [14], and molding techniques $[15,16]$ have been proposed to deposit thick PZT films. Although these methods can deposit PZT films over $5 \mu \mathrm{m}$ in thickness, the related reports primarily focus on the material analysis of the fabricated thick films. A sintering temperature greater than $550^{\circ} \mathrm{C}$ is required in these methods for high piezoelectricity. High temperature has hindered the application of these methods in MEMS fabrication when metals of relatively lower melting 
points are present. Furthermore, pattering thick PZT films to form microstructures could be difficult.

Wet etching is commonly used to pattern thin PZT films. Because PZT wet etching is approximately isotropic, severe lateral etching occurs as the PZT film thickness increases [17]. To avoid lateral etching, the lift-off process could be an alternative method to pattern thick PZT films. The photoresist adopted in the lift-off process has to sustain high sintering temperature, if the thick PZT films are deposited using previously mentioned methods. It has been observed that the removal of photoresist easily damages PZT films, even if the photoresist could sustain high sintering temperatures [12]. Therefore, the liftoff process cannot be used to pattern thick PZT films unless a low-temperature deposition method is employed. Although dry etching has been developed to pattern PZT films, its popularity has been obstructed by associated toxic gas production and high costs [18]. Other methods of patterning thick PZT films include molding [15] and dicing [19] techniques. However, they can only make simple patterns and the feature size cannot easily be smaller than $100 \mu \mathrm{m}$.

The aerosol deposition method was originally invented by Akedo and co-workers [20-22]. Its deposition rate for PZT films is greater than that of all the aforementioned methods. In addition, associated low annealing temperatures of PZT films have made aerosol deposition methods suitable in MEMS fabrication [23,24]. PZT films of thickness from $1 \mu \mathrm{m}$ to more than $100 \mu \mathrm{m}$ have been deposited by using the aerosol deposition method. To pattern thick PZT films, shadow masks have been employed during film deposition. Although it is simple and convenient, the sidewall with a $60^{\circ}$ inclination would be induced by this manner [22].

This paper presents a process that fabricates thick PZT structures with micrometer feature sizes. The PZT film was deposited at room temperature by a deposition method, and the lift-off method was used to pattern PZT structures. This non-heating deposition gives flexible design rules of PZT microstructures in MEMS fabrication. The deposited PZT films exhibit an apparent perovskite phase after room temperature deposition. Based on our aerosol deposition setup, we will show a standardized PZT process through the demonstration of a PZT thick cantilever beam. The functionality of the fabricated cantilever beam will be discussed.

\section{Methodology}

\subsection{Aerosol deposition method}

Fig. 1 shows the configuration of the aerosol deposition equipment in this work. The primary principle of aerosol deposition is to accelerate PZT particles to impact the substrates at high speed. As a result, the PZT film can be produced due to particle densification [20]. It should be noted that the types and sizes of PZT particles dominate the piezoelectric performance of the devices after aerosol deposition. In this work, we used HCQtype PZT powders (hard-doped PZT), which were prepared by ELECERAM TECHNOLOGY Co. The average particle diameter of HCQ powders is $500 \mathrm{~nm}$. Hard-doped PZT powders are

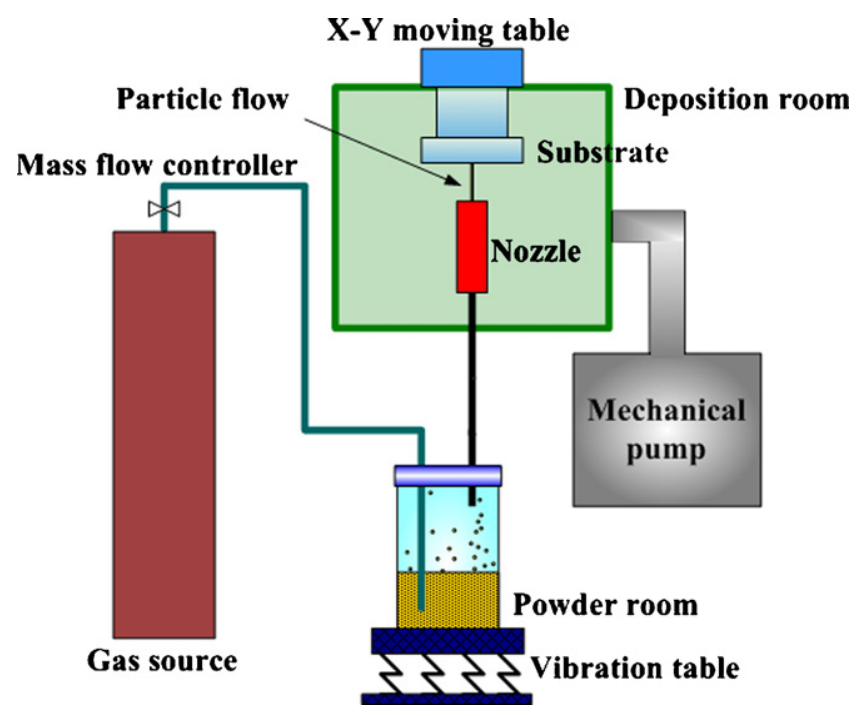

Fig. 1. Configuration of the aerosol deposition equipment.

usually used in piezoelectric transformers and power harvesting devices for their high quality factors. In our aerosol deposition setup, the deposition rate can be controlled by changing the moving speed of the X-Y stage. In an area of $60 \mathrm{~mm} \times 70 \mathrm{~mm}$, the optimum deposition rate was found to be $5 \mu \mathrm{m} / \mathrm{h}$. The surface roughness of the deposited PZT film is $100 \mathrm{~nm}$ for the film thickness of $10 \mu \mathrm{m}$. The substrate materials, such as $\mathrm{Si}, \mathrm{SiO}_{2}, \mathrm{SU}-8$, glass, parylene, polyimide, ITO, $\mathrm{Ni}, \mathrm{Cu}, \mathrm{Pt}, \mathrm{Au}$, and $\mathrm{Al}$, all show reliable adhesion to the PZT particles.

\subsection{MEMS-compatible process of thick PZT film}

In this work, we developed a special lift-off method to pattern thick PZT films. The selection of sacrificial layers plays an important role in our lift-off process. If the sacrificial layer is too soft, the PZT particles might penetrate through the sacrificial layer with high speed during aerosol deposition. The penetrated particles would be deposited on the substrate, resulting in the inaccurate control of PZT patterning. Conversely, PZT layers would be formed undesirably on the sacrificial layer if the sacrificial layer is too stiff. In this case, a conforming PZT layer, which connects the PZT patterns with undesirable PZT layers, would be generated. When the lift-off process is being conducted, the residual stress in the photoresist might peel off the PZT patterns through the conforming layer. In our experiments, we found particular photoresist of the sacrificial layers, which exhibits poor adhesion to the PZT particles. The PZT conformation layers are barely formed on this kind of photoresist during aerosol deposition. Without forming such conformation layers, the effect of residual stress could be reduced. Therefore, intact PZT patterns can be obtained.

Fig. 2 shows the flowchart of our MEMS-compatible process for fabricating thick PZT films. A $<100>$ silicon wafer with a thin $\mathrm{SiO}_{2}$ isolation layer is used as the substrate onto which PZT films are deposited. First, potassium hydroxide is used to etch the substrate from the backside until a silicon pattern of $100 \mu \mathrm{m}$ in thickness is left. The $\mathrm{Si}_{3} \mathrm{~N}_{4}$ layer is used as the etching mask 
(a)

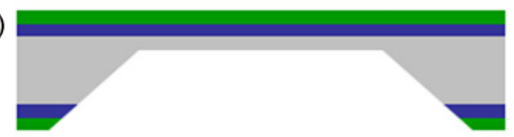

(b)
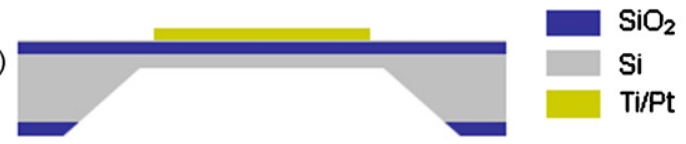

(c)

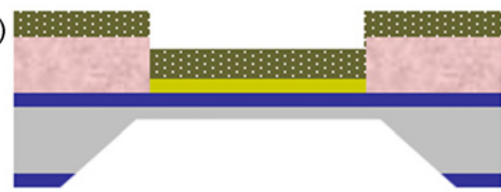

(d)

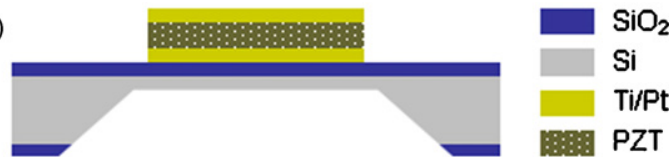

(e)

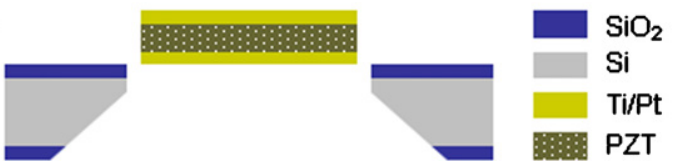

Fig. 2. PZT thick film process flowchart: (a) KOH etching the backside of silicon until $100 \mu \mathrm{m}$ thick silicon pattern is left; (b) evaporating Ti/Pt film and defining the pattern of bottom electrode; (c) depositing thick PZT film by aerosol deposition method, followed by patterning the PZT film using lift-off process; (d) evaporating and defining Ti/Pt film to form top electrode; (e) releasing PZT structure by using deep dry etching silicon.

and should be removed after this wet etching step. Afterward, the bottom electrode, PZT layer, and top electrode are deposited and patterned sequentially. Platinum serves as the electrode material and a titanium adhesion layer is used. The annealing of the deposited PZT layer can be conducted before or after the top electrode is patterned. Then, the Ti/Pt/PZT/Ti/Pt structure can be released by completely removing the silicon underneath using deep reaction ion etching (DRIE). The fabricated structure is suspended and supported by PZT itself. Finally, poling of the PZT films is performed. The deposition rate of HCQ-type PZT powders using an aerosol deposition method can be changed from 3 to $10 \mu \mathrm{m} / \mathrm{h}$ in a $60 \mathrm{~mm} \times 70 \mathrm{~mm}$ area. Using the optimized deposition rate of $5 \mu \mathrm{m} / \mathrm{h}$, the finest feature size of PZT structures can be obtained. In the lift-off process, the thickness of the sacrificial layer should be controlled within 40-60 $\mu \mathrm{m}$ if the designated thickness of the PZT film is designed under $20 \mu \mathrm{m}$. By using the developed thick film process, the cantilever beam micro-resonators have been fabricated for demonstration.

\section{Material properties}

The material properties of the deposited PZT films have been measured using different apparati. Fig. 3 shows the scanning

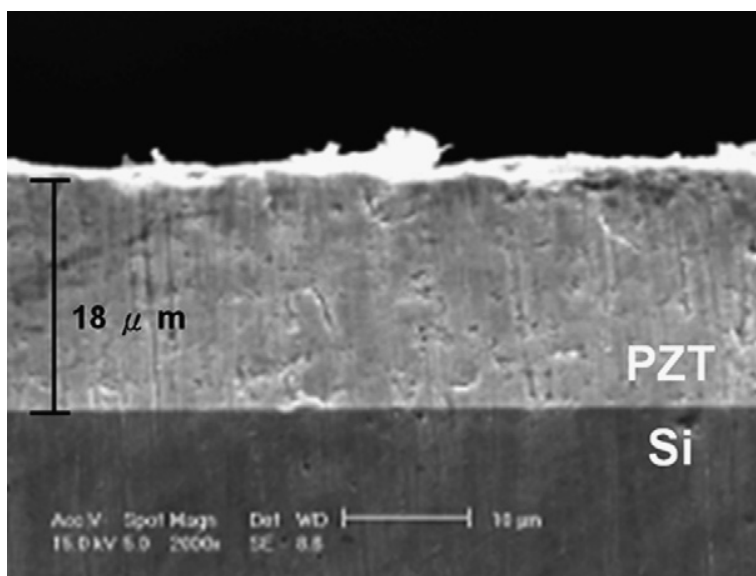

Fig. 3. SEM micrograph of cross section of $18 \mu \mathrm{m}$ thick PZT film.

electronic microscopy (SEM) picture of a cross section of PZT film. In this work, the thickness of the deposited PZT film is found to be $18 \mu \mathrm{m}$. It can be observed that PZT particles are densely packed to form a thick film and cracks are barely found. The deposition rate in this sample is $10 \mu \mathrm{m} / \mathrm{h}$, and the deposition area is $60 \mathrm{~mm} \times 70 \mathrm{~mm}$. The surface roughness of the PZT film is $1 \mu \mathrm{m}$; this larger surface roughness is caused by the higher deposition rate. The crystalline phases of the PZT powders and the deposited thick film with different annealing temperatures are characterized by X-ray diffraction (XRD). The measurement result in Fig. 4 indicates that the PZT powders have a perovskite phase, which remains in the thick film after room temperature deposition. A stronger perovskite phase can be obtained at higher annealing temperatures. After $650^{\circ} \mathrm{C}$ annealing, we observed that the sample has a more apparent perovskite phase than the sample without annealing.

The $P-E$ curve of $4.5 \mu \mathrm{m}$ thick PZT film after $650^{\circ} \mathrm{C}$ annealing was determined by a ferroelectric analyzer (TF ANALYZER 2000, aixACCT Co.). The electrical field used in the measurement was $750 \mathrm{kV} / \mathrm{cm}$, and the signal frequency was $100 \mathrm{~Hz}$. The measured $P-E$ curve is given in Fig. 5. The remanent polarization

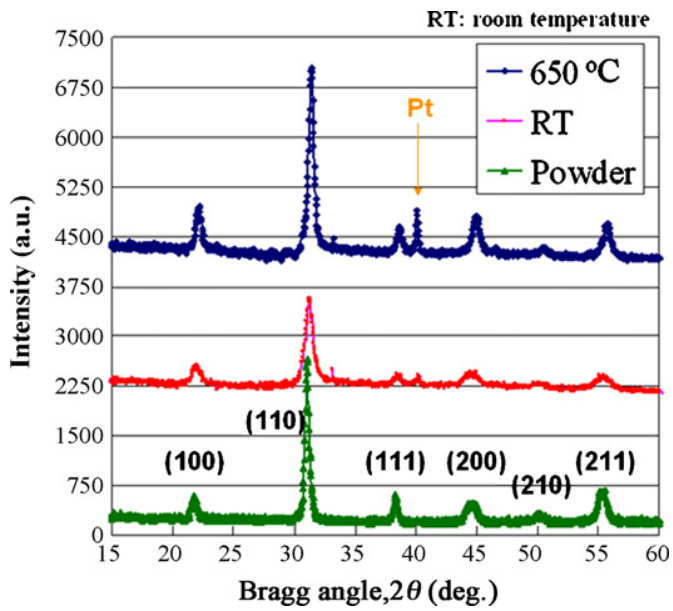

Fig. 4. X-ray diffraction scans of HCQ-type PZT powders and films with different temperature. The PZT film possesses perovskite phase after room temperature deposition. 


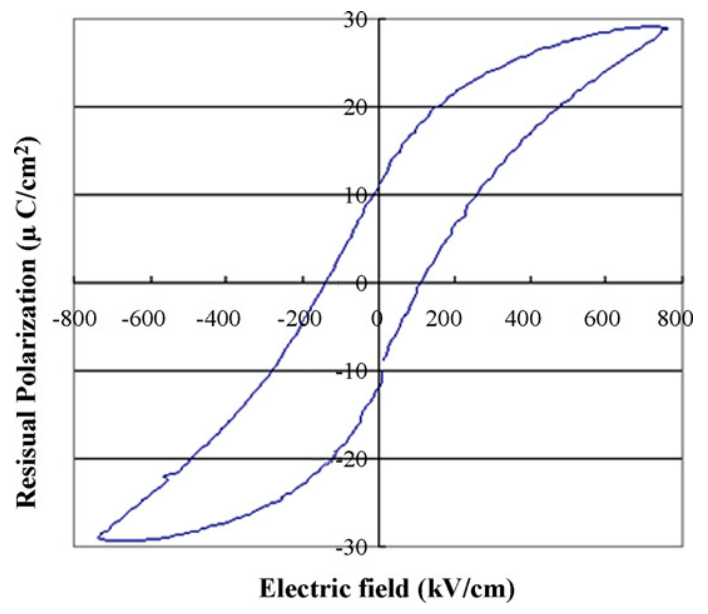

Fig. 5. $P-E$ curve of HCQ-type PZT after $650^{\circ} \mathrm{C}$ annealing.

and coercive field are $11 \mu \mathrm{C} / \mathrm{cm}^{2}$ and $100 \mathrm{kV} / \mathrm{cm}$, respectively. The relative dielectric constant and dielectric loss at $10 \mathrm{kHz}$ are 400 and 3\%, respectively. As anticipated, the relative dielectric constant of the deposited film is lower than that of soft-doped PZT material. A hard-doped PZT material would have a higher quality factor, lower relative dielectric constant, lower dielectric loss, and lower coercive field relative to the soft-doped material. We verified this comparison by characterizing an MD-type soft-doped PZT powder, which was also prepared by ELECERAM TECHNOLOGY Co. The relative dielectric constant and dielectric loss of the soft-doped PZT were found to be 770 and $4 \%$, respectively.

\section{Results and discussions}

For PZT films of $13 \mu \mathrm{m}$ in thickness, the minimum linewidth of $30 \mu \mathrm{m}$ was created using our fabrication technique, as shown in Fig. 6. The surface roughness of the PZT films is $100 \mathrm{~nm}$. In addition to line shapes, a more complicated PZT pattern has been fabricated, as shown in Fig. 7. Smooth corners with the minimum radius of $50 \mu \mathrm{m}$ were achieved.

Suspended micro-cantilever beams of thick PZT film were produced in this work. The thickness of the fabricated PZT layer is over $5 \mu \mathrm{m}$, which is stiff enough to mechanically support the suspended structure without generating any cracks. Fig. 8 shows a suspended microstructure formed by four joint PZT cantilever beams. This structure was created using the process given in Fig. 2, and the thickness of these beams was $15 \mu \mathrm{m}$. Vertical sidewalls of the PZT film can be observed in Fig. 8.

To verify the functionality of the PZT device fabricated by our aerosol deposition method, a $7 \mu \mathrm{m} \times 700 \mu \mathrm{m} \times 900 \mu \mathrm{m}$ Ti/Pt/PZT/Ti/Pt cantilever beam was made. Fig. 9 shows the fabricated cantilever beam array on a silicon wafer. The thicknesses of the Pt and Ti layers were 120 and $15 \mathrm{~nm}$, respectively. The thickness of the PZT film was 6.7-7.3 $\mu \mathrm{m}$ and the roughness of the PZT film was $100 \mathrm{~nm}$. Annealing of the PZT film was conducted at $650^{\circ} \mathrm{C}$ for $2 \mathrm{~h}$ and the poling condition was $5 \mathrm{~V} / \mu \mathrm{m}$ in an electric field at $150^{\circ} \mathrm{C}$ for $30 \mathrm{~min}$. The PZT cantilever beam was characterized in the frequency domain

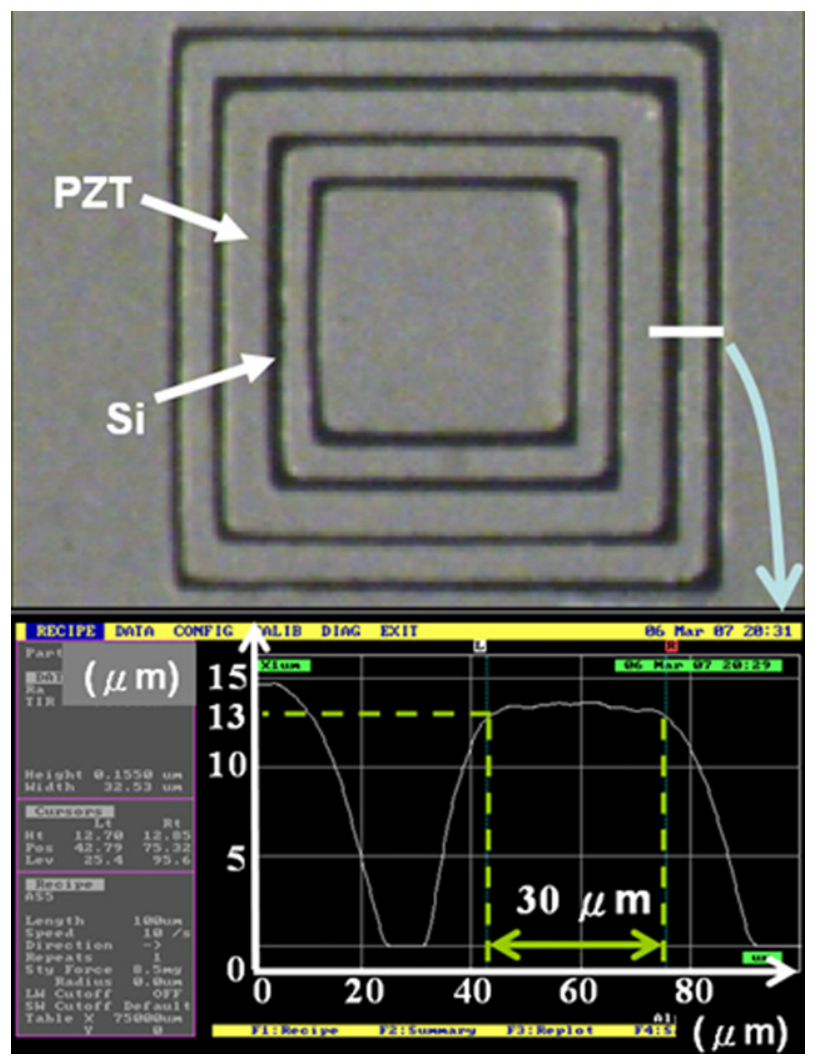

Fig. 6. Pattern of $13 \mu \mathrm{m}$ thick PZT structure with $30 \mu \mathrm{m}$ in width fabricated by lift-off process.

with phase signals given by an impedance analyzer (HP4294, Hewlett-Packard Development Co.). The magnitude of the phase signals was $0.5 \mathrm{~V}$. Finite element simulations in the frequency domain of $2.5 \mathrm{~Hz}$ to $4 \mathrm{MHz}$ were also performed to verify the experiments. A comparison of the measurement and simulation results is depicted in Fig. 10. The measurement result agrees with the simulation result. The deviation between these results may be caused by the non-uniformity of the PZT film thickness.

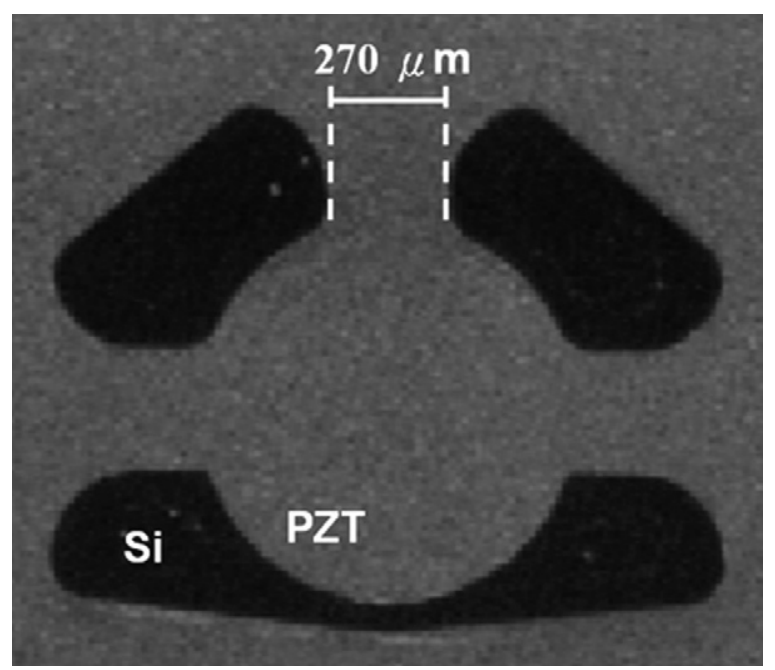

Fig. 7. A complex pattern of $10 \mu \mathrm{m}$ thick PZT film. 


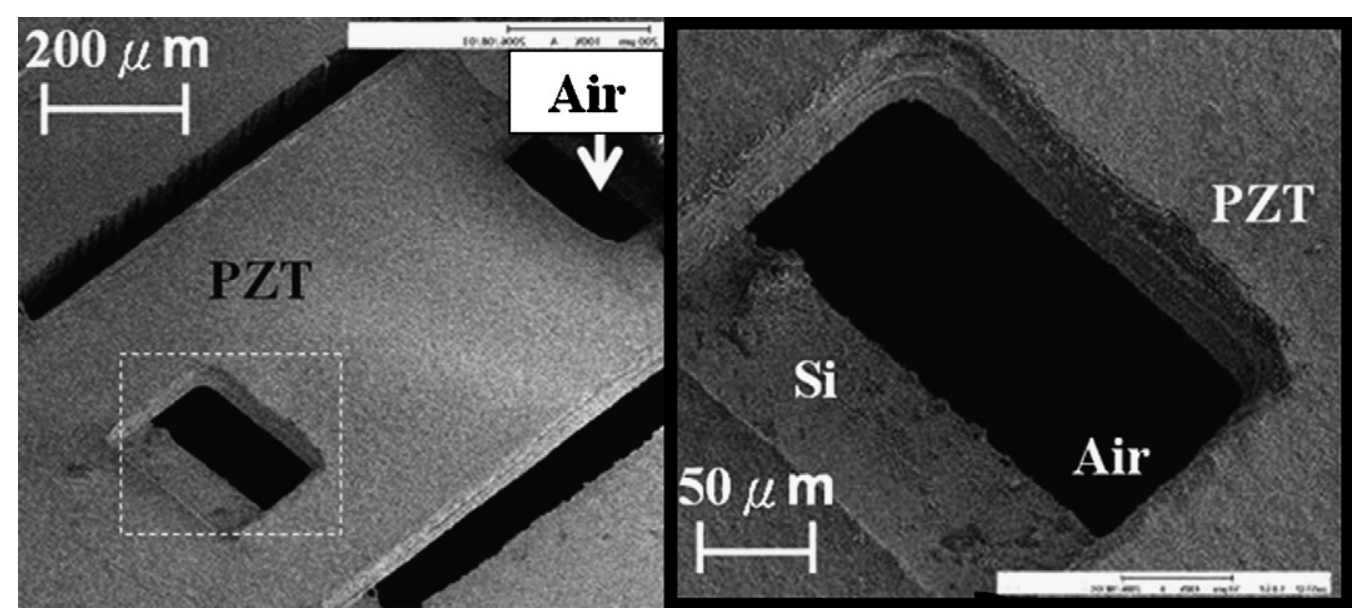

Fig. 8. SEM micrograph of a four-beam PZT structure.

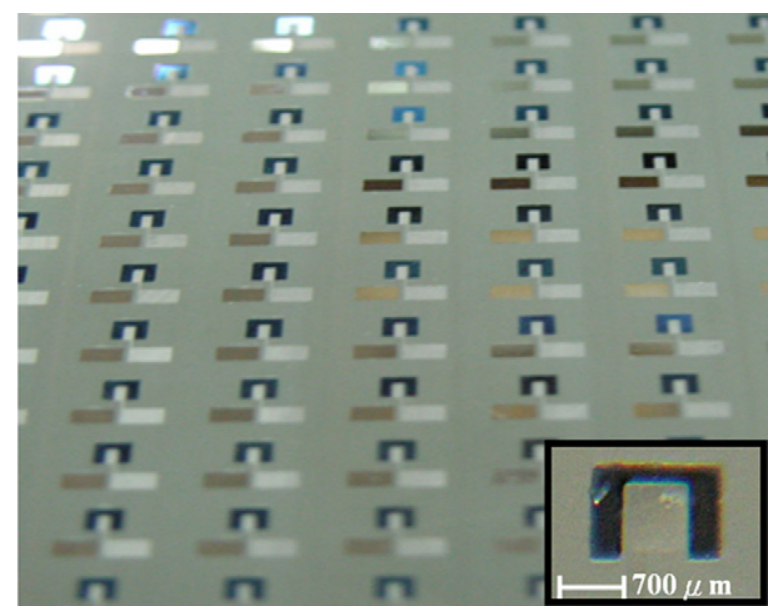

Fig. 9. PZT cantilever resonator array on Si wafer.

Finally, a $5 \mu \mathrm{m} \times 650 \mu \mathrm{m} \times 1200 \mu \mathrm{m}$ workable Ti/Pt/PZT/ Ti/Pt cantilever beam, which was annealed at $500{ }^{\circ} \mathrm{C}$ for $3 \mathrm{~h}$, was also tested. The thicknesses of the $\mathrm{Pt}$ and Ti layers were 120 and $15 \mathrm{~nm}$, respectively. The poling condition was $5 \mathrm{~V} / \mu \mathrm{m}$ in the electric field at $150^{\circ} \mathrm{C}$ for $30 \mathrm{~min}$. Fig. 11 demonstrates the measured signals of the first and third longitudinal resonance frequencies.

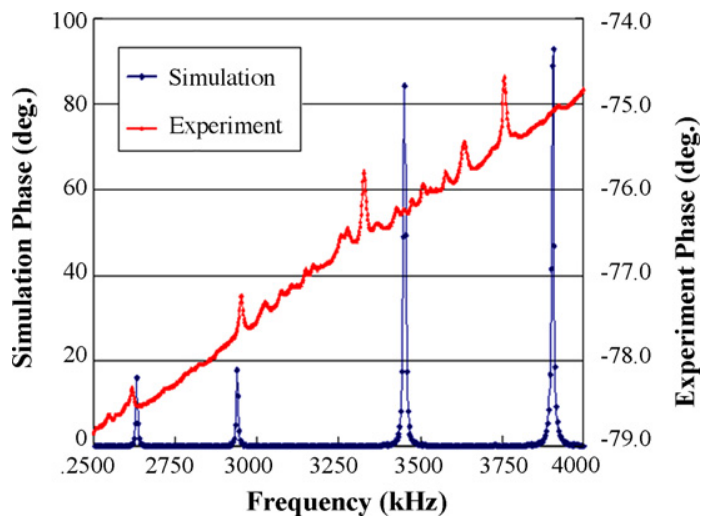

Fig. 10. Comparison of simulation and experimental results of PZT cantilever resonator.
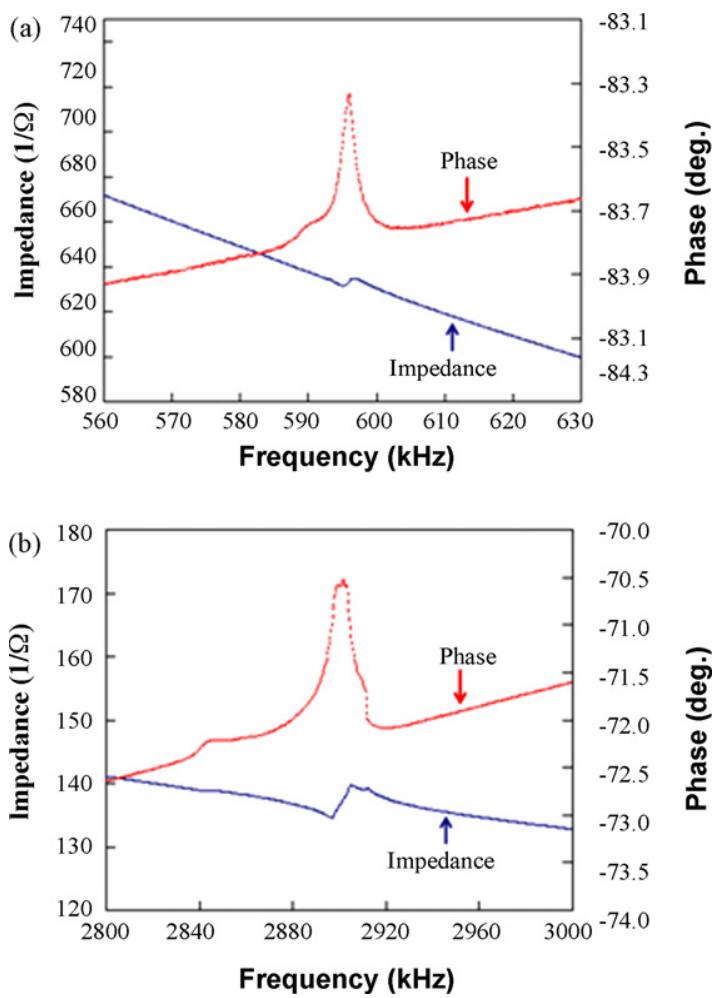

Fig. 11. Frequency response of $5 \mu \mathrm{m} \times 650 \mu \mathrm{m} \times 1200 \mu \mathrm{m}$ PZT cantilever resonator after $500^{\circ} \mathrm{C}$ annealing. (a) The first longitudinal resonance frequency; (b) the third longitudinal resonance frequency.

\section{Conclusion}

A novel MEMS-compatible PZT thick film process has been developed. PZT films can be deposited at room temperature by an aerosol deposition method, and the thickness of these films can be varied from $2 \mu \mathrm{m}$ to over $15 \mu \mathrm{m}$. In this work, a high deposition rate of $5 \mu \mathrm{m} / \mathrm{h}$ in a $60 \mathrm{~mm} \times 70 \mathrm{~mm}$ area were found to be the optimum parameters. Using the developed process, a $13 \mu \mathrm{m}$ thick PZT film with the minimum linewidth of $30 \mu \mathrm{m}$ was created, which can be patterned to form any complex twodimensional shape. 
To demonstrate the functionality of the fabricated PZT devices, a $7 \mu \mathrm{m} \times 700 \mu \mathrm{m} \times 900 \mu \mathrm{m}$ cantilever beam was constructed. The measured resonant frequencies agree with finite element simulations. The perovskite phase of the PZT films remains after aerosol depositing at room temperature, which is an advantage that leads to annealing temperatures lower than $500{ }^{\circ} \mathrm{C}$.

\section{Acknowledgements}

This research was funded by the National Science Council of Taiwan with the project number: NSC 95-2622-E-002-003. The authors would like to thank Prof. Lung-Jieh Yang at TKU MEMS Lab at Tamkang University for their fabrication facility supports. The authors would also like to thank Prof. TzongLin Shieh, Shih-Yung Pao, Chi-Ming Fang, Chun-Ming Huang, Sheng-Yuan Chung, and Cheng-Fan Wei at Taiwan University for their technical supports. The devices were fabricated at NTU NEMS Research Center at National Taiwan University.

\section{References}

[1] J. Fang, K. Wang, K.F. Böhringer, Self-assembly of PZT actuators for micropumps with high process repeatability, J. Microelectromech. Syst. 15 (2006) 871-878.

[2] T. Morita, M.K. Kurosawa, T. Higuchi, A cylindrical shaped micro ultrasonic motor utilizing PZT thin film, Sens. Actuators A 83 (2000) 225-230.

[3] T. Kanda, T. Morita, M.K. Kurosawa, T. Higuchi, A flat type touch probe sensor using PZT thin film vibrator, Sens. Actuators A 83 (2000) 67-75.

[4] Y.B. Jeon, R. Sood, J.H. Jeong, S.G. Kim, MEMS power generator with transverse mode thin film PZT, Sens. Actuators A 122 (2005) 16-22.

[5] S.K. Kim, Y.H. Seo, Fabrication and characterization of the piezoelectric microtransformer based on microelectromechanical systems, Appl. Phys. Lett. 88 (2006) 263510.

[6] D. Vasic, E. Sarraute, F. Costa, P. Sangouard, E. Cattan, Piezoelectric microtransformer based on PZT unimorph memebrane, J. Micromech. Microeng. 14 (2004) S90-S96.

[7] L. Pintilie, I. Boerasu, M.J.M. Gomes, M. Pereira, Properties of $\mathrm{Pb}\left(\mathrm{Zr}_{0.92} \mathrm{Ti}_{0.08}\right) \mathrm{O}_{3}$ thin films deposited by sol-gel, Thin Solid Films 458 (2004) 114-120.

[8] T. Hata, S. Kawagoe, W. Zhang, K. Sasaki, Y. Yoshioka, Proposal of new mixture target for PZT thin films by reactive sputtering, Vacuum 51 (1998) 665-671.

[9] X. Pu, W. Luo, A. Ding, H. Tian, P. Qiu, Preparation of PZT thick films by one-step firing sol-gel process, Mater. Res. Bull. 36 (2001) 1471-1478.

[10] K.L. Gentry, J.M. Zara, S.D. Bu, C.B. Eom, S.W. Smith, Thick film sol gel PZT transducer using dip coating, in: IEEE Ultrason. Symp., San Juan, Puerto Rico, October 22-25, 2000, pp. 977-980.

[11] H. Jacobsen, H.J. Quenzer, B. Wagner, K. Ortner, T. Jung, High-rate sputtering of thick PZT layers for MEMS actuators, in: MEMS'2006, Istanbul, Turkey, January 22-26, 2006, pp. 214-217.

[12] S.B. Beeby, A. Blackburn, N.M. White, Processing of PZT piezoelectric thick films on silicon for microelectromechancial systems, J. Micromech. Microeng. 9 (1999) 218-229.

[13] R.A. Dorey, R.W. Whatmore, S.P. Beeby, R.N. Torah, N.M. White, Screen printed PZT thick films using composite film technology, Integr. Ferroelectr. 54 (2003) 651-658.

[14] T. Kanda, M.K. Kurosawab, H. Yasuia, T. Higuchi, Performance of hydrothermal PZT film on high intensity operation, Sens. Actuators A 89 (2001) 16-21.

[15] H.J. Zhao, T.L. Ren, J.S. Liu, L.T. Liu, Z.J. Li, High quality PZT thick films using silicon mold technique for MEMS applications, in: Transducer '03, Boston, MA, USA, June 8-12, 2003, pp. 923-926.
[16] S.N. Wang, J.F. Li, R. Toda, R. Watanabe, K. Minami, M. Esashi, Novel processing of high aspect ratio 1-3 structures of high density PZT, in: MEMS'2006, Istanbul, Turkey, January 22-26, 2006, pp. $223-$ 228.

[17] K. Zheng, J. Lu, J. Chu, A novel wet etching process of $\mathrm{Pb}\left(\mathrm{Zr}\right.$, Ti) $\mathrm{O}_{3}$ thin films for applications in microelectromechanical system, Jpn. J. Appl. Phys. 43 (2004) 3934-3937.

[18] R.J. Zeto, B.J. Rod, M. Dubey, M.H. Ervin, R.C. Piekarz, S. TrolierMcKinstry, T. Su, J.F. Shepard, High-resolution dry etch patterning of PZT for piezoelectric MEMS devices, in: ISAF '98, Montreux, August 24-27, 1998, pp. 89-92.

[19] T. Lilliehorn, S. Johansson, Fabrication of multilayer 2D ultrasonic transducer microarrays by green machining, J. Micromech. Microeng. 14 (2004) 702-709.

[20] J. Akedo, Aerosol deposition method for fabrication of nano crystal ceramic layer, Mater. Sci. Forum 449-452 (2004) 43-48.

[21] J. Akedo, M.S. Lebedev, Baba Aerosol deposition method for preparation of lead zirconate titanate thick layer at low temperature-improvement of electrical properties by irradiation of fast atom beam and plasma, Jpn. J. Appl. Phys. 42 (2003) 5931-5935.

[22] M. Lebedev, J. Akedo, Patterning properties of PZT thick films made by aerosol deposition, Ferroelectrics 270 (2002) 117-122.

[23] M. Lebedev, J. Akedo, Y. Akiyama, Actuation properties of lead zirconate titanate thick films structured on $\mathrm{Si}$ membrane by the aerosol deposition method, Jpn. J. Appl. Phys. 39 (2000) 5600-5603.

[24] J.H. Park, J. Akedo, H. Sato, High-speed metal-based optical microscanners using stainless-steel substrate and piezoelectric thick films prepared by aerosol deposition method, Sens. Actuators A 135 (2007) 86-91.

\section{Biographies}

Xuan-Yu Wang received the BS degree in civil engineering from National Chi Nan University, Nantou, Taiwan in 2002. He is currently a doctor candidate of National Taiwan University, Taipei, Taiwan. His current research interests are in the area of MEMS and functional films.

Chi-Yuan Lee received his MS degree from Tamkang University, Taiwan in 1997 and PhD degree from the Department of Mechanical Engineering of National Taiwan University, Taiwan in 2004. He is currently an assistant professor at the Department of Mechanical Engineering, Yuan Ze University, Taiwan. His current research interests are in the areas of MEMS, acoustic devices and micro-fuel cell.

Cheng-Jien Peng received the BS degree in metallurgical \& materials engineering from National Cheng-Kung University, Tainan, in 1977, the MS degree in materials science \& engineering from National Tsing-Hua University, Hsinchu, in Taiwan, in 1988, and the $\mathrm{PhD}$ degree in solid state science from Pennsylvania State University, State College, PA, in 1994. His PhD dissertation was about the ferroelectric thin films for memory applications. He has joined the Materials Research Laboratories/Industrial Technology Research Institute, Taiwan since 1982. His current research interests are in the area of functional films, MEMS sensors and actuators.

Pei-Yen Chen received both BS and MS degrees in power mechanical engineering from National Tsing Hua University, Hsin-Chu, Taiwan, in 1980 and 1982, and the PhD degree in theoretical and applied mechanics from Cornell University, Ithaca, New York, in 1990. His PhD dissertation was about the vibration suppression of flexible structures using active feedback control. He has worked in the Chung-Shan Institute of Science and Technology, Tao-Yuan, Taiwan, since 1982. His current research interests are in the areas of MEMS and multidisciplinary coupling study.

Pei-Zen Chang received the BS degree in civil engineering from National Taiwan University, Taipei, Taiwan, in 1984, and the PhD degree in theoretical and applied mechanics from Cornell University, Ithaca, NY, in 1991. He joined the faculty of Institute of Applied Mechanics, National Taiwan University in 1991 and became a professor in 1999. His current research interests are in the area of micromachined sensors and actuators. 